\title{
MODEL PEMBELAJARAN KOOPERATIF QUESTION STUDENT HAVE (QSH) UNTUK MENINGKATKAN AKTIVITAS DAN PRESTASI BELAJAR SISWA KELAS XI SMAN 5 PEKANBARU
}

\author{
Chadmelia Igga Mustika, Erviyenni, Maria Erna \\ Laboratorium Pendidikan Kimia Kampus Bina Widya FKIP UNRI \\ E-mail : tika_cim@yahoo.com
}

\begin{abstract}
Abstrak
Penerapan model pembelajaran kooperatif Question Student Have telah dilaksanakan di kelas XI SMA Negeri 5 Pekanbaru bertujuan untuk meningkatkan aktivitas dan prestasi belajar siswa pada pokok bahasan kelarutan dan hasil kali kelarutan. Penelitian ini berbentuk eksperimen dengan desain pretest-posttest. Sampel penelitian terdiri dari kelas XI IPA 4 sebagai kelas eksperimen dan XI IPA 6 sebagai kelas kontrol yang dipilih secara acak dari dua kelas yang homogen. Kelas eksperimen diterapkan model pembelajaran kooperatif Question Student Have sedangkan kelas kontrol tanpa penerapan model pembelajaran kooperatif Question Student Have. Teknik pengambilan data menggunakan lembar observasi dan teknik tes. Berdasarkan hasil pengamatan aktivitas belajar kelas eksperimen selama proses telah melakukan kegiatan belajar sesuai dengan model yang diterapkan dan diperoleh thitung $>$ ttabel $(2,258>1,67)$ berarti penerapan model pembelajaran kooperatif Question Student Have dapat meningkatkan prestasi belajar siswa pada pokok bahasan kelarutan dan hasil kali kelarutan di kelas XI SMA Negeri 5 Pekanbaru, dengan peningkatan sebesar 6,53 \%. Model pembelajaran kooperatif Question Student Have dapat dijadikan sebagai salah satu alternatif model pembelajaran untuk meningkatkan aktivitas dan prestasi belajar siswa khususnya pada pokok bahasan Kelarutan dan Hasil Kali Kelarutan.
\end{abstract}

Kata Kunci : Kooperatif, Question Student Have, Aktivitas dan Prestasi Belajar

\begin{abstract}
The implementation of cooperative learning model Question Student Have been implemented in Class XI SMAN 5 Pekanbaru aims to increase the activity and student achievement on the subject of the solubility and solubility product. This study is experimental with pretest-posttest design. The research sample consisted of grade XI IPA 4 as an experiment and as a class XI IPA 6 controls were randomly selected from two classes homogeneous. Applied experimental class of cooperative learning model Question Student Have whereas the control class without the application of the cooperative model Question Student Have. Data collection techniques use the observation sheet and test Based on observations of classroom learning activities has conducted experiments during the process of learning activities in accordance with the model applied and obtained tcount $>t$ table $(2.258>1.67)$ means the implementation of cooperative learning models Question Student Have can improve student achievement on the subject of solubility and product solubility in class XI SMA 5 Pekanbaru, with an increase of $6.53 \%$.
\end{abstract}

Keywords: cooperative Question Student Have, activity and Learning Achievement 


\section{PENDAHULUAN}

Belajar merupakan aktivitas seseorang untuk mengetahui, memahami serta mengerti sesuatu yang menyebabkan terjadi perubahan tingkah laku pada diri seseorang. Kegiatan belajar merupakan kegiatan paling pokok dalam keseluruhan proses pendidikan disekolah (Slameto, 2003). Kegiatan belajar dalam pendidikan formal tidak terlepas dari proses kegiatan belajar di sekolah. Agar proses pembelajaran berjalan dengan baik, maka seorang guru selain menguasai materi, dituntut juga menguasai model yang dapat mengaktifkan siswa dalam proses pembelajaran. Guru merupakan salah satu faktor yang penting dalam menentukan berhasilnya proses belajar mengajar di dalam kelas. Guru harus mampu mewujudkan langkah-langkah inovatif dan kreatif agar proses belajar-mengajar lebih bermakna (Slameto, 2003). Dimyati (2006) menyatakan bahwa untuk meningkatkan proses belajar siswa, guru harus bisa memilih dan menerapkan cara pembelajaran yang tepat agar siswa lebih aktif dan termotivasi dalam proses belajar sehingga dapat meningkatkan prestasi belajar siswa.

Kimia adalah ilmu pengetahuan alam yang mempelajari tentang materi yang meliputi struktur, susunan, sifat, dan perubahan materi serta energi yang menyertainya. Pokok bahasan dalam mata pelajaran kimia sifatnya tidak hanya menghafal, tetapi dibutuhkan juga pemahaman dan analisis. Pokok bahasan kelarutan dan hasil kali kelarutan merupakan pokok bahasan yang membutuhkan pemahaman dan perhitungan yang baik. Untuk itu diperlukan usaha agar materi itu dapat bertahan lama diingatan peserta didik.

Sesuai pengamatan dan wawancara dengan guru bidang studi kimia SMA Negeri 5 Pekanbaru proses pembelajaran dilaksanakan secara konvensional, proses pembelajaran terpusat pada guru, komunikasi lebih banyak satu arah dari guru ke siswa karena proses pembelajaran dengan menjelaskan secara mendetail dianggap mudah dan sangat membantu siswa dalam mempelajari ilmu kimia yang masih diperkirakan sulit. Kegiatan menjelaskan informasi cenderung menjadikan suasana belajar menjadi kaku, siswa kurang aktif, siswa belum paham walaupun materi telah diajarkan, aktivitas dan keterlibatan siswa dalam proses pembelajaran jauh dari memadai. Aktivitas yang masih dianggap kurang dalam proses pembelajaran adalah kegiatan dalam mengajukan pertanyaan tentang materi yang kurang bahkan belum dimengerti, yang sangat berpengaruh terhadap kualitas pembelajaran dan prestasi belajar yang berdampak 
kepada penguasaan siswa dan dapat menyebabkan materi pelajaran selanjutnya juga tidak dapat dipahami secara utuh.

Alternatif yang diharapkan dapat mengatasi permasalahan kurangnya aktivitas dan keterlibatan siswa dalam proses pembelajaran adalah dengan model pembelajaran kooperatif Question Student Have (Pertanyaan dari siswa). Question Student Have (QSH) merupakan model yang dapat dipakai untuk mengetahui kebutuhan dan harapan siswa terhadap materi yang tidak dipahaminya secara tertulis (Hisyam Zaini, $d k k, 2008$ ). Guru memberikan tugas kepada siswa untuk membuat pertanyaan tentang materi yang tidak dipahami dan pertanyaan dibuat oleh siswa setelah guru menyampaikan materi pelajaran (Agus Suprijono, 2013).

Model QSH sangat baik digunakan pada siswa yang kurang berani mengungkapkan pertanyaan, keinginan dan harapan-harapannya melalui percakapan. Pemberian tugas kepada siswa untuk membuat pertanyaan dengan model pembelajaran kooperatif QSH akan berpengaruh positif terhadap prestasi belajar siswa dan mampu meningkatkan pemahaman siswa terhadap materi pelajaran (Fink dalam Hartono, 2008).

Berdasarkan uraian yang telah dikemukakan, maka pada penelitian ini bertujuan untuk meningkatkan keaktifan dan prestasi belajar siswa pada pokok bahasan kelarutan dan hasil kali kelarutan dengan penerapan model pembelajaran kooperatif QSH di kelas XI SMA Negeri 5 Pekanbaru dan menentukan besarnya peningkatan prestasi belajar siswa pada pokok bahasan kelarutan dan hasil kali kelarutan di kelas XI SMA Negeri 5 Pekanbaru setelah dilakukan penerapan model pembelajaran kooperatif QSH.

\section{METODE PENELITIAN}

Bentuk penelitian merupakan penelitian eksperimen dengan desain pretestposttest yang dilaksanakan di kelas XI SMA Negeri 5 Pekanbaru semester genap T.P 2013/2014. Populasi penelitian adalah keseluruhan siswa kelas XI yang terdiri dari 6 kelas. Sampel dalam penelitian dipilih dari dua kelas yang homogen dengan cara melakukan uji normalitas dan uji homogenitas terhadap nilai materi prasyarat dari hasil kali kelarutan, maka didapatkan kelas XI IPA 4 dan XI IPA 6 sebagai sampel. Hipotesis dalam penelitian ini adalah penerapan model pembelajaran kooperatif QSH dapat meningkatkan aktivitas dan prestasi belajar siswa pada pokok bahasan kelarutan dan hasil kali kelarutan di kelas XI SMA Negeri 5 Pekanbaru. 
Penelitian menggunakan rancangan randomized control group pretest-posttest. Sebelum diberi perlakuan, kedua kelas diberikan pretest kemudian diberi perlakuan dengan menerapkan model pembelajaran kooperatif QSH pada kelas eksperimen sedangkan kelas kontrol tidak menggunakan model pembelajaran kooperatif QSH. Setelah proses pembelajaran, kedua kelas diberikan posttest.

Langkah - langkah teknik analisis data dalam penelitian adalah :

1. Prasyarat Analisis

a. Uji Normalitas

Uji normalitas dilakukan untuk melihat apakah data terdistribusi secara normal atau tidak. Pengujian statistik dapat dilakukan berdasarkan kriteria bahwa data yang diolah berdistribusi normal. Uji ini dilakukan pada data materi prasyarat, data pretest dan data posttest. Dengan rumus :

$$
L=\frac{0,886}{\sqrt{n}}
$$

(Agus Irianto, 2010)

b. Uji Homogenitas

Uji homogenitas dilakukan untuk memperlihatkan bahwa kedua kelompok sampel berasal dari populasi yang memiliki varians yang sama. Data yang digunakan untuk uji homogenitas adalah data dari hasil tes uji homogenitas (materi prasyarat) yang telah terdistribusi normal. Untuk menghitung varians dari masing-masing sampel digunakan rumus:

$$
\mathrm{S}_{1}^{2}=\frac{n_{1} \sum F i X_{i-}^{2}\left(\sum F i X_{i}\right)^{2}}{n_{1}\left(n_{1}-1\right)} \quad \mathrm{S}_{2}^{2}=\frac{n_{2} \sum F i X_{i}^{2}-\left(\sum F i X_{i}\right)^{2}}{n_{2}\left(n_{2}-1\right)}
$$

Pengujian homogenitas varians menggunakan uji $\mathrm{F}$ dengan rumus :

$$
\mathrm{F}=\frac{\text { Varians Terbesar }}{\text { VariansTerkecil }}
$$

\section{Uji Hipotesis}

Dilakukan uji-t pihak kanan dengan kriteria probabilitas ( 1- $\alpha$ ) untuk menguji hipotesis, dengan rumus sebagai berikut :

$$
\mathrm{t}=\frac{\bar{x}_{1}-\bar{x}_{2}}{S_{g} \sqrt{\frac{1}{n_{1}}+\frac{1}{n_{2}}}} \quad \text { dengan } \quad S_{g}^{2}=\frac{\left(n_{1}-1\right) S_{1}^{2}+\left(n_{2}-1\right) S_{2}^{2}}{n_{1}+n_{2}-2}
$$


Kriteria pengujian hipotesis penelitian diterima apabila $t_{\text {thitung }}>t_{\text {tabel }}$ dimana $t_{\text {tabel }}$ didapat dari daftar disribusi $\mathrm{t}$ dengan $\mathrm{dk}=\mathrm{n}_{1}+\mathrm{n}_{2}-2$ dengan taraf nyata $\alpha=0,05$. Besarnya peningkatan prestasi belajar siswa ditunjukkan dengan rumus $K p$ sebagai berikut:

$$
\mathrm{Kp}=\mathrm{r}^{2} \times 100 \%
$$

Nilai : $\quad t=\frac{r \sqrt{n-2}}{\sqrt{1-r^{2}}} \quad$ sehingga menjadi $\quad r^{2}=\frac{t^{2}}{t^{2}+n-2}$

Keterangan rumus:

$\mathrm{r}^{2} \quad=$ Koefisien determinasi

$\mathrm{Kp} \quad=$ Koefisien pengaruh

(Riduwan, 2003)

\section{HASIL DAN PEMBAHASAN}

Pengolahan data hasil penelitian dilakukan dengan teknik analisa data menggunakan metode statistik, meliputi prasyarat analisis dengan uji normalitas. Hasil uji normalitas data materi prasyarat sampel 1 dan sampel 2 memiliki $\mathrm{L}_{\max } \leq \mathrm{L}$ tabel maka dapat disimpulkan bahwa ke dua sampel berdistribusi secara normal (Tabel 1). Data materi prasyarat yang berdistribusi normal diuji kehomogenannya. Data yang telah diuji variansnya selanjutnya diuji kesamaan rata-rata dua pihak untuk mengetahui kehomogenan dua kelas.

Tabel 1. Hasil Uji Homogenitas

\begin{tabular}{|c|c|c|c|c|c|c|c|}
\hline Sampel & $\mathbf{n}$ & $\sum \mathbf{X}$ & $\bar{x}$ & $\mathbf{F}_{\text {tabel }}$ & $\mathbf{F}_{\text {hitung }}$ & $\mathbf{t}_{\text {tabel }}$ & $\mathbf{t}_{\text {hitung }}$ \\
\hline Sampel 1 & 5 & 720 & 77,7143 & \multirow{2}{*}{1,74} & \multirow{2}{*}{1,48} & \multirow{2}{*}{2,00} & \multirow{2}{*}{0,9358} \\
\hline Sampel 2 & 0 & 964 & 74,1 & & & & \\
\hline
\end{tabular}

Keterangan :

$\mathrm{n} \quad=$ jumlah siswa

$\sum \mathrm{X}=$ jumlah nilai Materi Prasyarat

$\bar{x}=$ nilai rata-rata Materi Prasyarat

Uji varians untuk data kedua sampel diperoleh $F_{\text {hitung }}(1,48)<F_{\text {tabel }} \quad(1,74)$, menunjukkan bahwa kedua kelompok sampel mempunyai varians yang sama (homogen). Uji kesamaan rata - rata kedua sampel diperoleh nilai thitung terletak antara $t_{\text {tabel }}$ dan tabel $(-2,00<0,9358<2,00)$, yang dapat memberikan indikasi bahwa rata-rata sampel 1 sama dengan rata-rata sampel 2 atau dapat dikatakan homogen. Kedua sampel yang homogen ditentukan secara acak dan didapat kelas XI IPA 4 sebagai kelas 
eksperimen dan kelas XI IPA 6 sebagai kelas kontrol. Data untuk analisis uji hipotesis dapat dilihat dari Tabel 2.

Tabel 2. Hasil Uji Hipotesis

\begin{tabular}{cccccccc}
\hline Kelas & $\mathbf{N}$ & $\sum \mathbf{X}$ & $\overline{\boldsymbol{x}}$ & $\mathbf{S}_{\mathbf{g a b}}$ & $\mathbf{t}_{\text {tabel }}$ & $\mathbf{t}_{\text {hitung }}$ & $\mathbf{K p}$ \\
\hline Eksperimen & 40 & 2488 & 62,2 & 15,1448 & 1,66 & 2,258 & $6,53 \%$ \\
Kontrol & 35 & 1900 & 54,2857 & & & & \\
\hline
\end{tabular}

Keterangan :

$n \quad=$ jumlah siswa yang menerima perlakuan

$\sum X \quad=$ jumlah nilai selisih pretest dan posttest

$\bar{X} \quad=$ nilai rata-rata selisih pretest dan posttest

Aktivitas belajar siswa selama proses diamati dengan lembar observasi yang dirancang sesuai sintaks model pembelajaran kooperatif QSH dan peningkatan prestasi belajar pada penelitian diketahui berdasarkan hasil analisis uji hipotesis dari data pretest dan posttest. Uji hipotesis dilakukan dengan menggunakan uji t pihak kanan, $H_{1}$ diterima jika memenuhi kriteria thitung $>$ tabel dengan $\mathrm{dk}=\mathrm{n}_{1}+\mathrm{n}_{2}-2$, kriteria probabilitas $1-\alpha$ yaitu 0,95 . Hasilnya thitung $=2,258$ dan nilai tabel pada $\alpha=0,05$ dengan $\mathrm{dk}=73$ adalah 1,67. Uji hipotesis memenuhi syarat thitung $>\mathrm{t}_{\text {tabel }}(2,258>1,66)$ sehingga hipotesis pada penelitian dapat diterima dan penerapan model pembelajaran kooperatif QSH berpengaruh sebesar 6,53\% terhadap peningkatan prestasi belajar siswa.

Pembelajaran kooperatif dapat memotivasi siswa untuk berbagi dalam kelompok belajar, karena hasil dari kerja keras kelompok dalam meningkatkan kemampuan memperoleh pengetahuan akan diberikan penghargaan (Muslimin Ibrahim, 2003). Proses kegiatan belajar kooperatif QSH siswa dibimbing untuk melakukan serangkaian kegiatan seperti mendengarkan penjelasan materi dari guru, membaca materi pelajaran, mengerjakan LKS dalam diskusi kelompok dan membuat pertanyaan secara individu dalam kelompok - kelompok belajar, mempresentasikan jawaban LKS dan berdiskusi bersama guru untuk menjawab pertanyaan - pertanyaan individu dalam setiap kelompok. Penerapan model pembelajaran kooperatif QSH menghendaki siswa untuk membuat pertanyaan tentang materi yang tidak dipahami dalam secarik kertas yang disebut kartu pertanyaan (Silberman, 2001), karena kartu harus diisi dengan pertanyaanpertanyaan, maka dalam proses pembelajaran menghendaki siswa untuk membaca buku dan segera merancang pertanyaan yang relevan dengan permasalahan yang dihadapi. 
Model pembelajaran yang menggunakan pertanyaan merupakan salah satu cara efektif untuk mengembangkan cara berfikir dan aktivitas siswa dalam pembelajaran sehingga prestasi belajar siswa akan menjadi lebih baik. Menurut James, et al (dalam Nur Lia Khasanah, 2013) pertanyaan yang dibuat sendiri dapat membantu siswa dalam memahami materi yang dibaca. Penggunaan pertanyaan dalam pembelajaran dapat menjadikan siswa memperoleh pengalaman belajar secara maksimal dan mempunyai keinginan untuk mengetahui apa yang belum dipahami atau dialaminya (Chin dalam Nur Lia Khasanah, 2013). Dengan begitu siswa lebih mudah memahami materi atau konsep yang diberikan dan kemampuan berfikir siswa lebih berkembang.

Peningkatan aktivitas dan prestasi belajar siswa kelas eksperimen pada pokok bahasan Kelarutan dan Hasil Kali Kelarutan dengan model pembelajaran kooperatif QSH terjadi karena adanya serangkaian proses aktif siswa dalam pembelajaran sesuai sntaks. Nana Sudjana (2004) menyatakan keaktifan siswa dapat dilihat dari keikutsertaan dalam melaksanakan tugas belajar, terlibat dalam pemecahan masalah, bertanya kepada siswa lain atau guru apabila tidak memahami persoalan yang dihadapi, berusaha mencari berbagai informasi yang diperlukan untuk pemecahan masalah, melaksanakan diskusi kelompok sesuai dengan petunjuk guru, melatih diri dalam memecahkan soal dan mengerjakan LKS, siswa aktif bertanya ataupun menjawab pertanyaan, diskusi dan saling berbagi pengetahuan dengan teman sekelompok, mengemukakan pendapat dalam kelompok, saling membantu dalam menyelesaikan masalah.

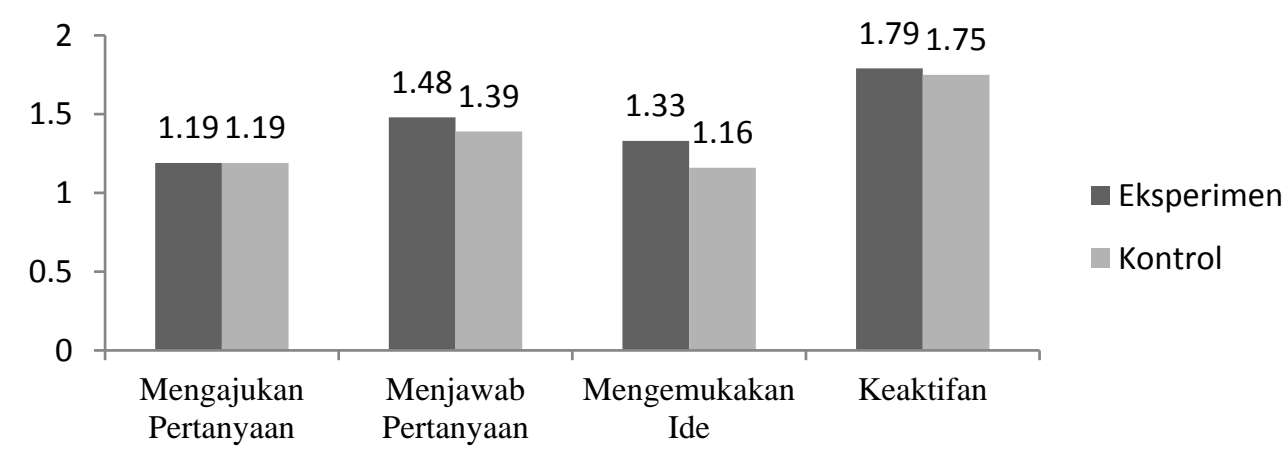

Gambar 1. Diagram Rekap Penilaian Afektif Siswa (Rata - Rata Dalam Empat Pertemuan)

Gambar 1 menunjukan bahwa pada setiap pertemuan nilai afektif kelas eksperimen lebih tinggi dibandingkan kelas kontrol artinya penerapan model 
pembelajaran kooperatif QSH mempengaruhi keaktifan belajar siswa. Menurut Slameto (2003) bila siswa menjadi partisipan yang aktif dalam proses pembelajaran, maka ia akan memiliki pengetahuan yang diperolehnya dengan baik dan pelajaran akan melekat lebih lama.

Kontribusi atau pengaruh penerapan model pembelajaran kooperatif QSH terhadap peningkatan prestasi belajar siswa dalam pokok bahasan kelarutan dan hasil kali kelarutan di kelas XI SMA Negeri 5 Pekanbaru yaitu sebesar 6,53 \%. Penerapan model pembelajaran kooperatif QSH dapat memotivasi siswa untuk belajar, dimana siswa aktif dalam membuat pertanyaan dan membaca buku untuk memperoleh ide dalam menuliskan pertanyaan yang akan diajukan. Dengan penerapan model pembelajaran kooperatif QSH siswa menjadi percaya diri dalam mengajukan pertanyaan dan tidak merasa takut untuk mempresentasekan materi terutama sesuai dengan Lembar Kerja Siswa (LKS) yang sudah dibahas dalam kelompok.

\section{KESIMPULAN DAN SARAN}

\section{Kesimpulan}

Berdasarkan hasil analisis data dan pembahasan dapat disimpulkan bahwa :

1. Penerapan model pembelajaran kooperatif QSH dapat meningkatkan aktivitas dan prestasi belajar siswa pada pokok bahasan Kelarutan dan Hasil Kali Kelarutan di kelas XI SMA Negeri 5 Pekanbaru.

2. Persentase peningkatan prestasi belajar kimia siswa melalui penerapan model pembelajaran kooperatif QSH pada pokok bahasan Kelarutan dan Hasil Kali Kelarutan di kelas eksperimen sebesar 6,53 \%

\section{Saran}

Setelah melakukan penelitian ini, beberapa hal yang direkomendasikan adalah :

1. Model pembelajaaran kooperatif QSH dapat dijadikan sebagai salah satu alternatif model pembelajaran untuk meningkatkan keaktifan dan prestasi belajar siswa khususnya pada pokok bahasan Kelarutan dan Hasil Kali Kelarutan.

2. Penggunaan model pembelajaran kooperatif QSH harus lebih mengontrol siswa dalam membuat pertanyaan sehingga siswa tidak mencontoh pekerjaan temannya. 


\section{DAFTAR PUSTAKA}

Agus Irianto. 2010. Statistik Konsep Dasar, Aplikasi dan Pengembangannya. Kencana. Jakarta

Agus Suprijono. 2013. Cooperative Learning Teori dan Aplikasi PAIKEM. Pustaka Pelajar. Yogyakarta

Dimyati, Mudjiono. 2006. Belajar dan Pembelajaran. Rineka Cipta. Jakarta

Hartono. 2008. Strategi Pembelajaran Aktif (Active Learning Strategy). http://sditalqalam,wordpress,com /2008/01/09/strategi-pembelajaran-activelearning/ (Diakses 26 Desember 2013)

Hisyam Zaini, Bermawy Munthe, Sekar Ayu Aryani. 2008. Strategi Pembelajaran Aktif. Pustaka Insan Madani. Yogyakarta

Muslimin Ibrahim. 2003. Model Pembelajaran Kooperatif. Unes Press. Surabaya

Nana Sudjana. 2011. Dasar - Dasar Proses Belajar Mengajar. Sinar Baru Algesindo. Bandung

Nur Liya Khasanah. 2013. Efektivitas Strategi Question Student Have dan Media Powerpoint pada Materi Struktur dan Fungsi Jaringan Tumbuhan. Journal of Biology Education 2 (1) : 70 - 71. FMIPA Universitas Negeri Semarang. Semarang

Silberman. 2008. Strategi Pembelajaran Aktif. Pustaka Insan Madani, Yogyakarta Sudjana. 2005. Metode Statistika. Tarsito. Bandung

Slameto. 2003. Belajar dan Faktor yang Mempengaruhinya. Rineka Cipta. Jakarta

Riduwan. 2003. Dasar-dasar Statistika. Alfabeta. Bandung 